\title{
Preparation of Activated Carbons from Waste External Thermal-Insulating Phenolic Foam Boards
}

\author{
Lijuan Gao ${ }^{1}$, Xiaojun Zheng ${ }^{1}$, Yaming Zhu ${ }^{1}$, Xuefei Zhao ${ }^{1 *}$, and Junxia Cheng ${ }^{1}$ \\ ${ }^{1}$ Engineering Research Center of Advanced Coal Coking and Efficient Use of Coal Resources, \\ University of Science and Technology Liaoning, 114051 Anshan China
}

\begin{abstract}
Activated carbons (ACs) were prepared by steam physical activation or $\mathrm{KOH}$ chemical activation with the waste external thermal-insulating phenolic foam board as the raw material. The Fourier transform infrared spectroscopy (FT-IR), X-ray diffraction (XRD), Brunauer-Emmett-Teller (BET) specific area, pore-size distribution and iodine value were used to characterize the properties of ACs. AC-1 (with the method of KOH chemical activation) has the iodine value of $2300 \mathrm{mg} / \mathrm{g}$, BET specific area of $1293 \mathrm{~m}^{2} \mathrm{~g}^{-1}$, average pore-size of $2.4 \mathrm{~nm}$, and mainly composed of micropore and relatively small mesopore. AC-2(with the method of steam physical activation) has the iodine value of $1665 \mathrm{mg} / \mathrm{g}$. Compared with AC-2, AC-1 had a pore-size distribution with more evenly and relative concentrated, it's belonging to the high microporosity materials. Actually, chemical activation had more significant influence on destruction of the pore wall than physical activation.
\end{abstract}

\section{Introduction}

As a kind of self-flame-retarded foam material, thermal-insulating phenolic foam boards are good at fire prevention and thermal insulation of buildings with its series remarkable performance. For example, hermal-insulating phenolic foam boards have the specialty of non-drop, non-soften small smoke amount, no diffusion flames, flame penetration resistance, fire retardancy and heat preservation and insulation [1, 2]. However, the recycling of waste treatment on thermal-insulating phenolic foam boards has been a new problem.

Activated carbon is an important carbon material with its good ability of high porosity, specific surface area, stable chemical property, easy regeneration and so on [3-5]. Activated carbons are extensively used as adsorbent, catalyst, catalyst carrier, gas or electric energy storage, electric double layer capacitor (EDLC) electrode material, in the fields of food, medicine, chemical industry, and environmental protection [6]. Actually, almost any carbonaceous material can be converted into activated carbon, and the preparation methods of ACs were predominately includes carbonization and activation [7-9]. Generally, the raw materials of ACs can be roughly divided into two categories of plants and minerals according

*Corresponding author: zhaoxuefei@163.com; gaolijuan@ustl.edu.cn 
to the sources [10-12]. Plant category includes wood, coconut shells, walnut shells, apricot, olive nuclear, and rice husk. Minerals category includes anthracite, asphalt and petroleum coke and. In recent years, a variety of wastes have been favored to produce ACs with their outstanding advantages of low producing cost, available, sufficient, high carbon content and nonpoisonous raw materials [13-15]. It's an excellent method to save resources and protect the ecological environment produce for produce ACs from wastes.

Thermal-insulating phenolic foam board is a kind of high quality carbon materials, and its wastes can be used as raw material during the production of ACs. It's a good method to saving resources and protecting ecological environment. In this paper, the properties of ACs prepared by two activation processes were carefully compared. It takes an important role to provide basis for the fundamental research on the utility value of waste phenolic foam and ACs preparation.

\section{Experiment}

\subsection{Pre-treatment of the raw material}

A certain quantity of waste external thermal-insulating phenolic foam boards were grounded and sieved to $21 \mu \mathrm{m}$, then dried in $120^{\circ} \mathrm{C}$ for 3 hours before use. The raw material has been named as RM. The pre-treatment waste phenolic foam was heated to $800{ }^{\circ} \mathrm{C}$ at the rate of 5 ${ }^{\circ} \mathrm{C} \cdot \mathrm{min}^{-1}$ with $\mathrm{N}_{2}$ as the protcetion gas, then holding for 60 minutes, and the obtained product numbered as $\mathrm{CP}$.

\subsection{Preparation of activated carbon}

Alkali activation. A certain amount of $\mathrm{CP}$ were homogeneous mixed with $\mathrm{KOH}$ solution $\left(0.1 \mathrm{~g} \cdot \mathrm{mL}^{-1}\right)$ at different weight ratio, and dipped for a certain hours. The rest materials were transferred to a corundum boat after eliminated the free water. Then the corundum boats were put to the activating oven for activation. Samples were naturally cooled to the ambient temperature after a certain activation time. The obtained activated samples have been cleaned by hydrochloric acid (5\%) and distilled water till to neutral $\mathrm{pH}$ value. The obtained activated carbons were dried to constant weight and calculated yield finally.

Steam activation. The corundum boat (with $1.0000 \mathrm{~g} \mathrm{CP}$ ) was put transferred to activated oven, and heated from ambient temperature to activation temperature at a certain rate with $\mathrm{N}_{2}$ as the inert atmosphere. The $\mathrm{N}_{2}$ was replaced by pre-set steam at the activation temperature. After a certain activation time, the steam was shut down and samples were cooled naturally within $\mathrm{N}_{2}$, and then gained the activated carbon.

\subsection{Characterization of samples}

FTIR analysis. Infrared (IR) spectra of pre-treatment materials and ACs were obtained using a PerkinElmer Spotlight-400 FTIR/NIR spectrometer at a resolution of $4 \mathrm{~cm}^{-1}$. Prior to FTIR analysis, $\mathrm{KBr}$ pellets were prepared by grinding the mixture of $1 \mathrm{mg}$ of sample with $150 \mathrm{mg}$ of $\mathrm{KBr}$.

XRD analysis. The samples (RM, CP, AC-1, and AC-2) were characterized on powder X-ray Diffraction (XRD) with the tube voltage of $40 \mathrm{kV}$, tube current of $40 \mathrm{~mA}$, scanning range from $10^{\circ} \sim 90^{\circ}$ and step size of $0.013^{\circ}$.

BET analysis. The Brunauer-Emmett-Teller (BET) has been used to analysis the pore structure of ACs. Actually, the ACs samples were characterized at fully automatic physical 
adsorption instrument (ASAP2020, American). The samples have been dried for $4 \mathrm{~h}$ at an vacuum drying oven before test.

Conventional analysis. The iodine adsorption value of activated carbon was tested using the standards of GB/T 7702.7-2008 (China).

\section{Results and discussion}

\subsection{Effects of steam activation parameters on the adsorptive property of activated carbon}

The effects of steam flow, activation temperature, and activation time on the yield and adsorptive property of activated carbon have been showed as Fig. 1. With the increase of steam flow, activation time and activation temperature, the yield of ACs decreased, and the iodine value showed a maximum value. This is related to that the yield was only affected by the extent of solution loss and ablation of charcoal. The greater of the extent, the lower of the yield. However, specific surface area, the pore shape and pore volume would of the ACs maybe lead to a lower iodine value.

The formation process of ACs was consisted of trepanning and bearizing. The iodine value has been increased during the trepanning stage. It can be illustrated by the stages of steam flow of 30-40 $\mathrm{g} \cdot \mathrm{h}^{-1}$ (Fig. 1(a)), activation time of 60-90 minutes (Fig. 1(b)) and activation temperature of $600-750{ }^{\circ} \mathrm{C}$ (Fig. 1(c)). Briefly, improved the pore parameters (number, diameter, volume and specific surface area) can brought more sufficient contact between steam and samples, and then deepened the activation level, as well as the faster reaction rate. During the bearizing stage, pore number remained constant, pore volume and specific surface area became lager. Nevertheless, excessive bearizing might make the pore wall thinner and even skeleton destruction occurs. These actually leading to the decrease in numbers and specific surface area of pore, which can be seen in the steam flow over $40 \mathrm{~g} \cdot \mathrm{h}^{-1}$ (Fig. 1(a)), activation time over 90 minutes (Fig. 1(b)) and activation temperature over 750 ${ }^{\circ} \mathrm{C}$ (Fig. 1(c)).

Taking iodine value and yield of activated carbon into account, the optimal parameters of steam activation were steam flow of $40 \mathrm{~g} / \mathrm{L}$, activation time of 90 minutes and activation temperature of $750{ }^{\circ} \mathrm{C}$. 

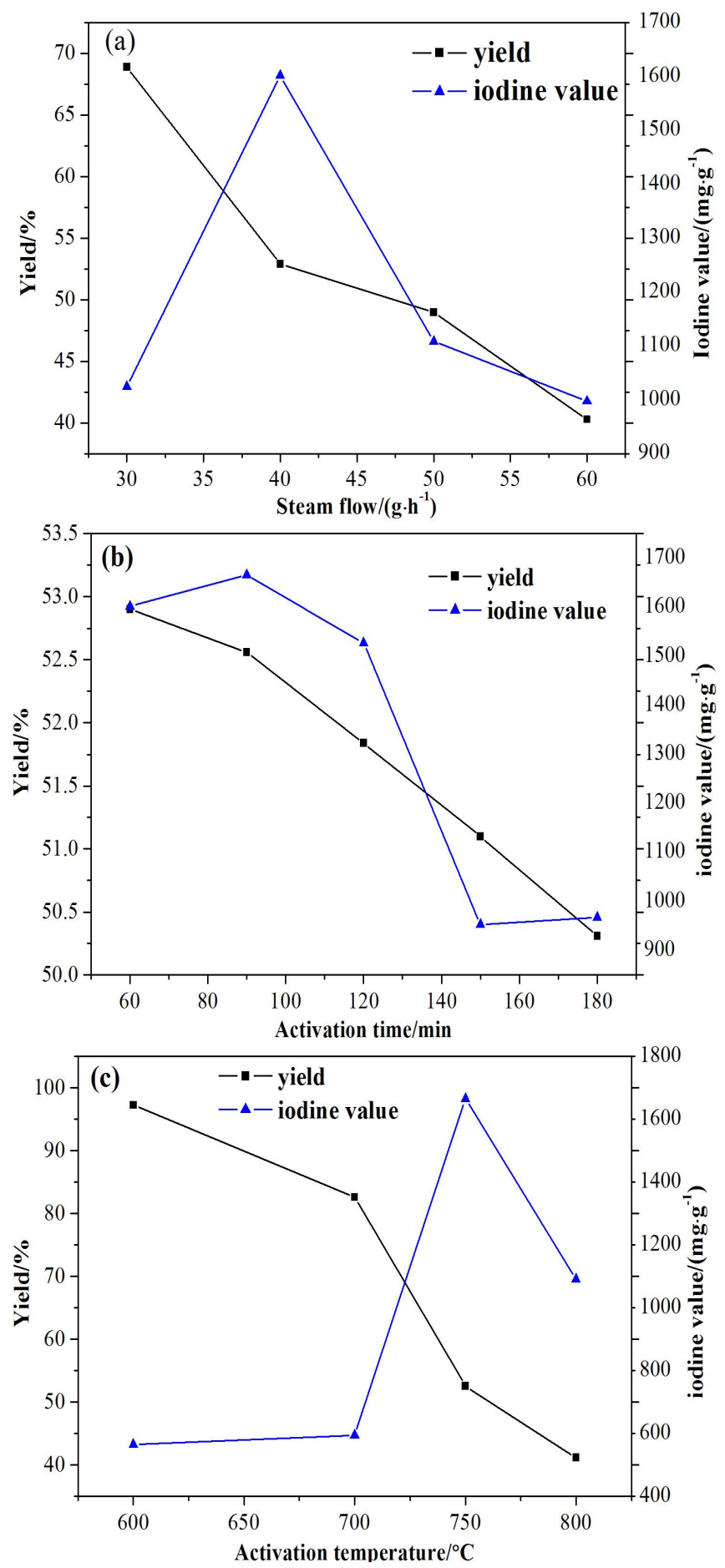

Fig. 1. Effects of steam activation parameters on the adsorptive property of activated carbons: (a) steam flow, (b) activation time, (c) activation temperature 


\subsection{Effects of alkali activation parameter on the adsorptive property of activated carbon}

Single factor experiment was applied to study the effects of immersion time, alkali-carbon ratio, activation temperature and activation time of $\mathrm{KOH}$ activation on the yield and iodine value of activated carbon, and have been shown in Fig. 2.
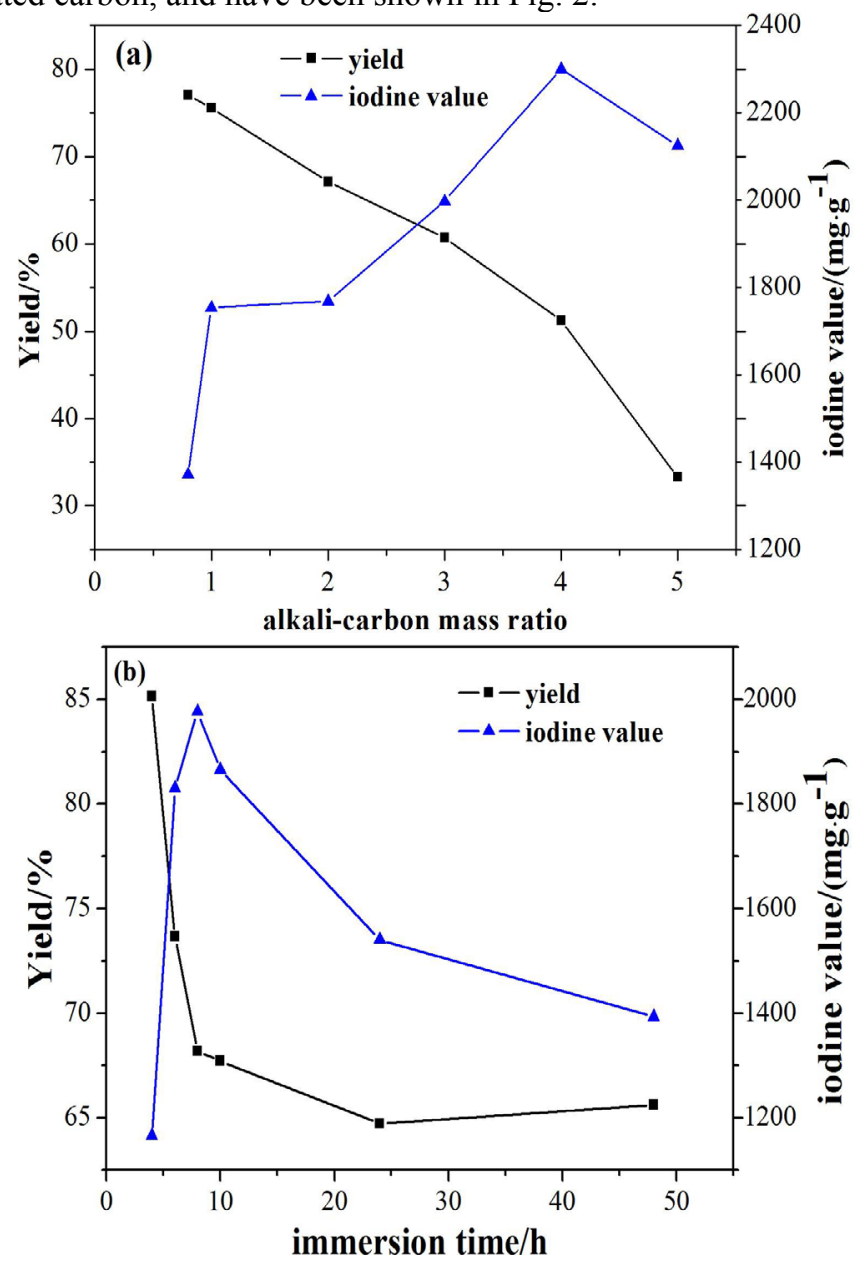

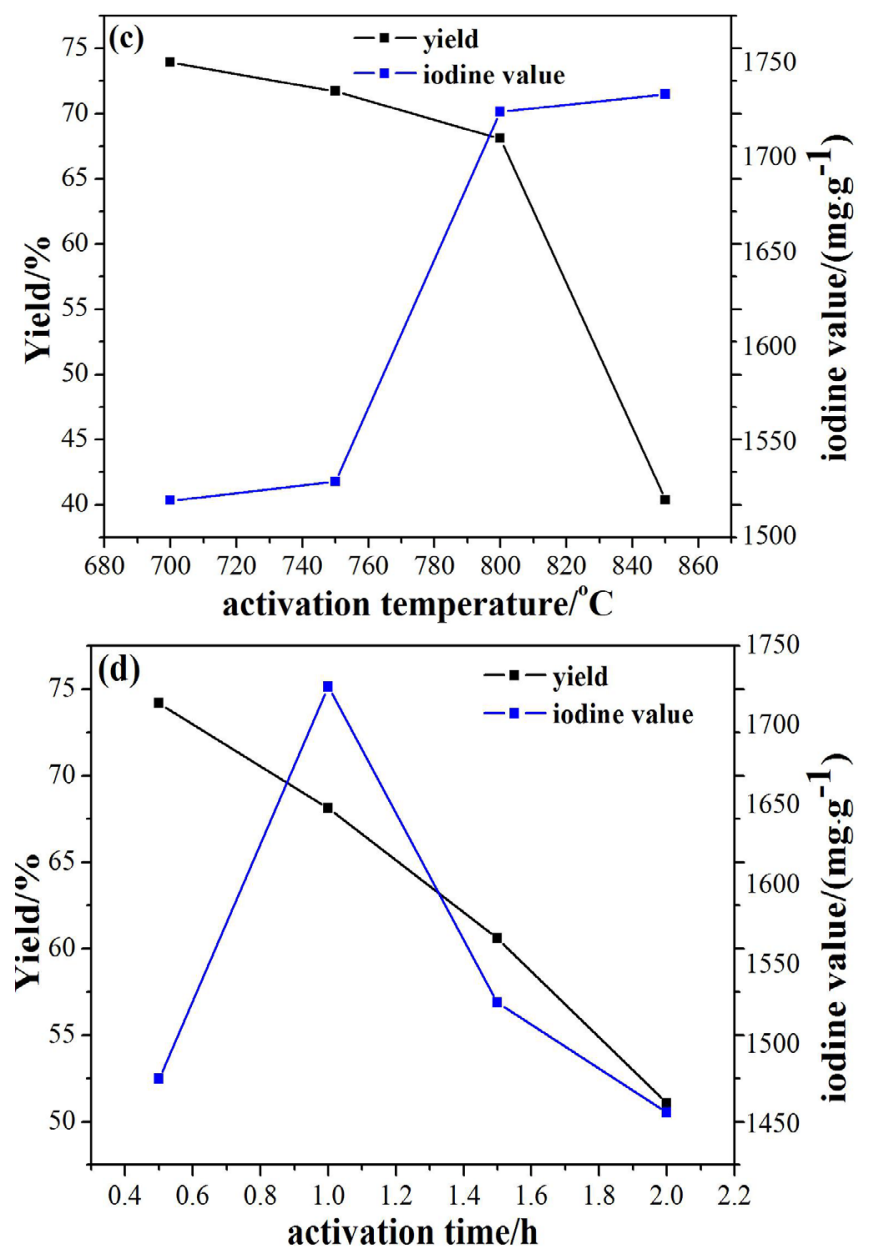

Fig. 2. Effects of $\mathrm{KOH}$ activation parameters on the adsorptive property of activated carbon: (a) alkali-carbon mass ratio, (b) immersion time, (c) activation temperature, (d) activation time

Either increasing alkali-carbon ratio or immersion time would expedite the bearizing stage (Fig. 1(a) and (b)). Briefly, the carbon skeletons which around the micorpore will continue react with activator and lead to the gradual collapse of the carbon skeleton. It also increased the number of mesopore and macropore, decrease in specific surface area, and decrease in iodine value as well.

Fig. 2(c) implicated the significant influence of activation temperature on the absorption ability of activated carbon. With the increase of activation temperature, the iodine value increased while yield decreased progressively $\left(750{ }^{\circ} \mathrm{C}\right.$ to $\left.800{ }^{\circ} \mathrm{C}\right)$, and then dramatically decreased with the continuing activation $\left(800{ }^{\circ} \mathrm{C}\right.$ to $\left.850{ }^{\circ} \mathrm{C}\right)$. This phenomenon can be translated by the chemical properties of $\mathrm{K}$. Briefly, The $\mathrm{K}$ has an melting point of $63.2^{\circ} \mathrm{C}$, boiling point of $765.5^{\circ} \mathrm{C}$ and density of $0.86 \mathrm{~g} \cdot \mathrm{cm}^{-3}$, and this properties resulted in the reaction between $\mathrm{KOH}$ activator and carbon particles was restricted on the surface (the oxygen-containing groups) during the lower temperature stage. This step was corresponding to the activation-induced stage, and belonging to the pre-activating stage of pore-forming and activation. During the high temperature activation stage, $\mathrm{K}$ was presented as liquid which can facilitating flowed in the micropores and reacted with more active sites. Hence, elevating temperature is conducive to formation of micropore inside the carbon particle. However, 
excessive activation temperature will increase the production cost and machine wear. With the opposite, the yield was decreased with the increase of activation temperature, because the content of destroyed carbon skeleton was increased.

Iodine value reached the maximum when the activated time holding for 60 minutes (Fig. 2(d)). Prolonging activation time, part of micropore may expand to mesopore or macropore, the $\mathrm{K}$ steam and other volatile gas might result in attenuation or burnthrough of pore wall which leading to the corrosion of carbon skeleton. It also destructed the pore structure and declined in the absorption ability of ACs. Similarly, with the carbon was ablated continually, the yield was persistently decreased.

Taking iodine value and yield of activated carbon into account, the optimal parameters of $\mathrm{KOH}$ activation were alkali-carbon ratio of 4 , immersion time of 8 hours, activation temperature of $800{ }^{\circ} \mathrm{C}$ and activation time of 60 minutes.

\subsection{Characteristic of activated carbon}

In order to compare the microstructure of activated carbons from different activation method, $\mathrm{RM}, \mathrm{CP}, \mathrm{AC}-1$ (the activated carbon which prepared with the optimal $\mathrm{KOH}$ activation method), and AC-2 (the activated carbon which prepared in the optimal steam activation method) were tested by FTIR, XRD, specific surface, volume and diameter of pore, respectively.

\subsection{FTIR and XRD analysis of ACs}

FTIR patterns of activated carbons and carbon precursor were showed in Fig. 3(a). Compared with raw material, most of absorption peaks and abundance of carbide reduced dramatically after carbonization. Such as alkane C-H stretching vibration $\left(3000 \sim 2850 \mathrm{~cm}^{-1}\right)$, aromatic ring C-H stretching vibration $\left(3100 \sim 3000 \mathrm{~cm}^{-1}\right)$, and C-H out-of-plane bending $\left(880 \sim 680 \mathrm{~cm}^{-1}\right)$ were disappeared. Only $\mathrm{C}=\mathrm{C}$ skeletal vibration $\left(1600 \sim 1450 \mathrm{~cm}^{-1}\right)$ can be found in the four samples. It have been indicated that carbonization and activation treatment can not only enhanced the carbon skeletal strength and aromaticity, but also made non-carbon elements into small molecules to escape at higher temperature. Compared with $\mathrm{AC}-1$, the abundance of phenol and ketone structure near $3443 \mathrm{~cm}^{-1}, 1645 \mathrm{~cm}^{-1}, 1593 \mathrm{~cm}^{-1}, 1473 \mathrm{~cm}^{-1}, 1445 \mathrm{~cm}^{-1}$ were relatively larger in $\mathrm{AC}-2$, and it fit for the mechanism of steam activation. 

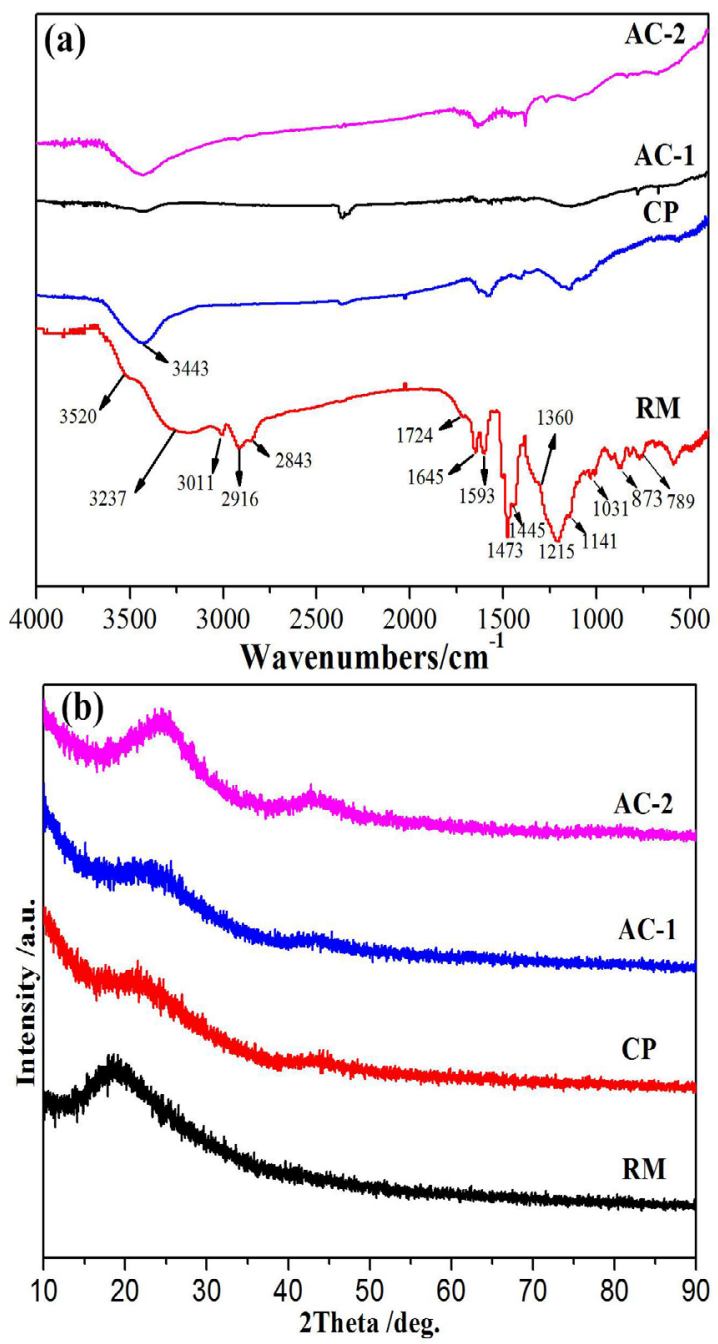

Fig. 3. FTIR (a) and XRD (b) patterns of the samples

As shown in the XRD patterns of ACs and carbon precursor (Fig. 3(b)), the characteristic diffraction peaks of (002) and (100) planes of multilayer graphite structure appeared when $2 \theta$ at around $25^{\circ}$ or $43^{\circ}$. The diffraction peaks of ACs crystal planes (002) and (100) were wider and the strength was lower than CP. It indicated that the carbon crystalline structure trends to amorphous carbon during the activation process. This phenomenon was more obvious in $\mathrm{AC}-2$ than in $\mathrm{AC}-1$.

\subsection{Specific surface area and pore diameter analysis of ACs.}

The specific surface area and pore diameter of the activated carbon samples were obtained by nitrogen absorption-desorption isotherm determined at $77 \mathrm{~K}$. According to the adsorption isotherm, the total specific surface area was calculated based on BET method, the pore diameter was calculated based on t-plot method, the distribution of pore size and mesopore volume were calculated based on Barrette Joynere Halenda (BJH) method, the total pore volume was calculated using the $\mathrm{N}_{2}$ absorption value at the relative pressure $\left(\mathrm{P} / \mathrm{P}_{0}\right)$ of 0.99 . The results have been shown in the table 1 . 
Table 1. BET surface area and pore structure parameters of activated carbon

\begin{tabular}{|c|c|c|c|c|c|c|}
\hline Sample & $\mathrm{S}_{\text {BET }}\left(\mathrm{m}^{2} / \mathrm{g}\right)$ & $\mathrm{V}_{\mathrm{t}}\left(\mathrm{cm}^{3} / \mathrm{g}\right)$ & $\mathrm{V}_{\text {mic }}\left(\mathrm{cm}^{3} / \mathrm{g}\right)$ & $\mathrm{V}_{\text {mes }}\left(\mathrm{cm}^{3} / \mathrm{g}\right)$ & $\mathrm{V}_{\text {mes }} / \mathrm{V}_{\mathrm{t}}(\%)$ & $\mathrm{D}_{\mathrm{p}}(\mathrm{nm})$ \\
\hline $\mathrm{AC}-1$ & 1293.45 & 0.708 & 0.40 & 0.297 & 41.95 & 2.4 \\
\hline $\mathrm{AC}-2$ & 786.82 & 0.70 & 0.13 & 0.60 & 85.71 & 3.54 \\
\hline
\end{tabular}

note: $S_{B E T}-B E T$ specific surface area, $V_{t}$ - pore volume, $V_{\text {mic }}-$ micorpore volume based on $t$-plot method, $V_{\text {mes }}$ - mesopore volume based on BJH method, $D_{p}$ - pore diameter
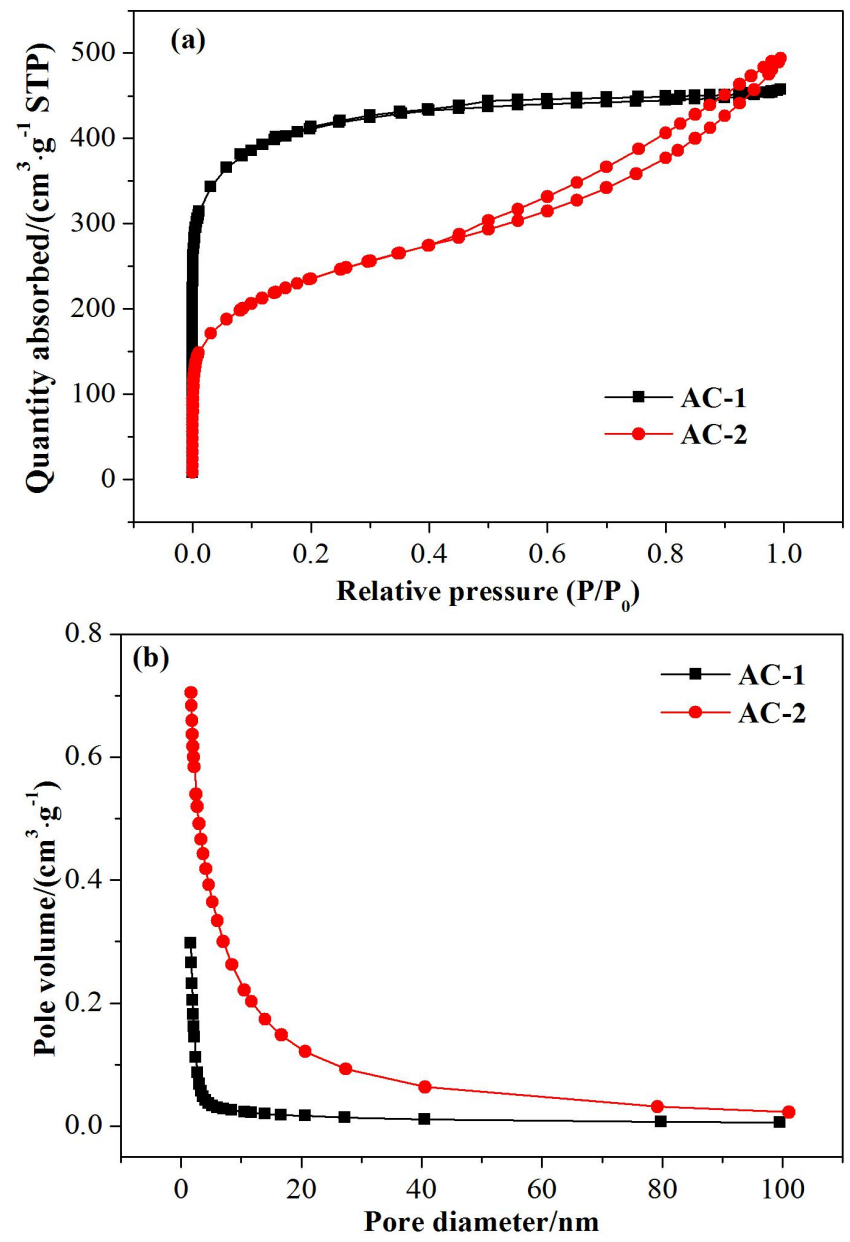

Fig. 4. $\mathrm{N}_{2}$ adsorption-desorption (a) and BJH adsorption pore size distribution (b) of the ACs

According to the IUPAC classification, the adsorption-desorption isotherm (Fig. 4(a)) of AC-1was basically match the type I, AC-2 exhibited type II, and hysteresis loop was basically match the type $\mathrm{H}_{3}$ hysteresis patterns. The absorption value of both ACs was increased dramatically with the increase of relative pressure $\left(\mathrm{P} / \mathrm{P}_{0}\right)$ in the beginning. This phenomenon was corresponding to the filling stage of micropore by $\mathrm{N}_{2}$. And then the increase tendency became gentle, which was corresponding to the multilayer adsorption of coarse mesopore and macropore. In addition, the condensation occurred inside the pore made a deviation between the isothermal adsorption and desorption isotherm. Since the rising 
tendency of AC-2 was higher than that of AC-2, it means that the AC-2 had a major proportion of mesopore and macropore than those of $\mathrm{AC}-1$.

It can be seen from the BJH adsorption distribution of pore size from Fig. 4(b). Most of pore size in AC-1 was less than $2 \mathrm{~nm}$, and coexisted with some mesopore with the size of 2-5 $\mathrm{nm}$. AC-1 has a uniform and concentrated distribution of pore size. AC-2 was mainly made up of mesopore, so the $\mathrm{N}_{2}$ absorption equilibrium was achieved quickly, and in line with the adsorption isotherm. The distribution of pore size on AC-2 has a characterized trailing unimodal. It illustrated that $\mathrm{AC}-2$ has an unevenly distribution of mesopore structure between $2 \mathrm{~nm}$ and $20 \mathrm{~nm}$, and contain a small number of macropore.

\section{Summary}

The waste external thermal-insulating phenolic foam boards were a kind of high level raw material to produce activated carbon. Both of activation methods and activation conditions have significantly influences on the absorption property of activated carbon. AC-1 was a kind of high quality activated carbon which mainly composed of micropore and mesopore (the iodine value was $2300 \mathrm{mg} \cdot \mathrm{g}^{-1}$, specific surface area $1295 \mathrm{~m}^{2} \cdot \mathrm{g}^{-1}$, average pore size $2.4 \mathrm{~nm}$ ) were activated by $\mathrm{KOH}$ with the ratio of alkali/carbon was $4: 1$, immersion time of 10 hours, activation temperature of $800{ }^{\circ} \mathrm{C}$ and activation time of 40 minutes. The AC-2 was mainly composed of 2-20 nm mesopore, the iodine value was $1665 \mathrm{mg} \cdot \mathrm{g}^{-1}$, specific surface area was $787 \mathrm{~m}^{2} \cdot \mathrm{g}^{-1}$. AC-2 was prepared by steam activation at the temperature of $750{ }^{\circ} \mathrm{C}$ for 90 minutes, and the steam flow was $40 \mathrm{~g} \cdot \mathrm{h}^{-1}$.

This work was supported by the National Natural Science Foundation of China (U1361126), the Specialized Research Fund for the Doctoral Program of Higher Education (20132120110001), the Young Teacher Foundation of University of Science and Technology Liao Ning (QN201625).

\section{References}

1. J. Mao, J. Chang, Y. Chen, D. Fang, Chemical Industry and Engineering, 15 (1998) 38.

2. H. Shen, A. J. Lavoie, S. R. Nutt, Composites Part A: Applied Science and Manufacturing, 34 (2003) 941.

3. D. Lozano-Castello, M. Lillo-Rodenas, D. Cazorla-Amoros, A. Linares-Solano, Carbon, 39 (2001) 741.

4. B. Acevedo, C. Barriocanal, I. Lupul, G. Gryglewicz, Fuel, 151 (2015) 83.

5. D. Lozano-Castello, D. Cazorla-Amoros, A. Linares-Solano, Energy \& Fuels, 16 (2002) 1321.

6. H. Teng, H. c. Lin, AIChE Journal, 44 (1998) 1170.

7. J. i. Hayashi, A. Kazehaya, K. Muroyama, A. P. Watkinson, Carbon, 38 (2000) 1873.

8. M. A. Islam, I. Tan, A. Benhouria, M. Asif, B. Hameed, Chemical Engineering Journal. 270 (2015) 187.

9. M. A. Islam, A. Benhouria, M. Asif, B. Hameed, Journal of the Taiwan Institute of Chemical Engineers (2015).

10. M. Munoz-Guillena, M. Illán-Gómez, J. Martin-Martinez, A. Linares-Solano, C. Salinas-Martinez de Lecea, Energy \& Fuels, 6 (1992) 9.

11. M. Greenbank, S. Spotts, Water Technol, 16 (1993) 56.

12. P. Hadi, M. Xu, C. Ning, C. S. K. Lin, G. McKay, Chemical Engineering Journal, 260 (2015) 895. 
13. I. Okman, S. Karagöz, T. Tay, M. Erdem, Applied Surface Science, 293 (2014) 138.

14. A. Elmouwahidi, Z. Zapata-Benabithe, F. Carrasco-Marín, C. Moreno-Castilla, Bioresource Technology, 111 (2012) 185.

15. C. Peng, X.-b. Yan, R.-t. Wang, J.-w. Lang, Y.-j. Ou, Q.-j. Xue, Electrochimica Acta, 87 (2013) 401. 